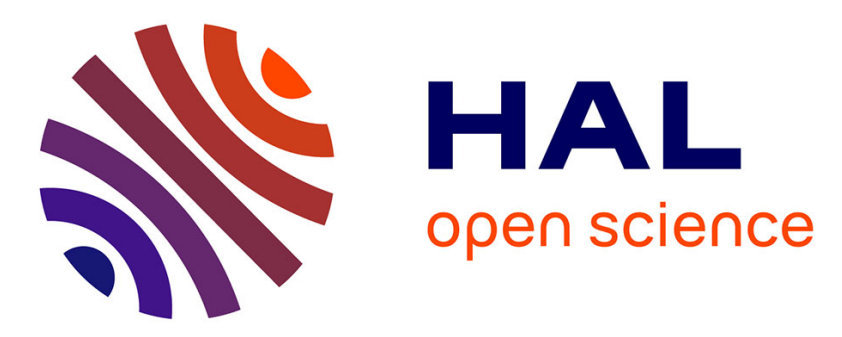

\title{
Iron-fortified formula use in young children and association with socioeconomic factors in the French nationwide ELFE cohort
}

Anne-Sylvia Sacri, Blandine de Lauzon-Guillain, Marie-Noëlle Dufourg, Corinne Bois, Marie Aline Charles, Martin Chalumeau

\section{To cite this version:}

Anne-Sylvia Sacri, Blandine de Lauzon-Guillain, Marie-Noëlle Dufourg, Corinne Bois, Marie Aline Charles, et al.. Iron-fortified formula use in young children and association with socioeconomic factors in the French nationwide ELFE cohort: Iron-fortified formula use and socioeconomic factors. Acta Paediatrica, 2019, 108 (7), pp.1285-1294. 10.1111/apa.14682 . inserm-02093132

\section{HAL Id: inserm-02093132 https://www.hal.inserm.fr/inserm-02093132}

Submitted on 8 Apr 2019

HAL is a multi-disciplinary open access archive for the deposit and dissemination of scientific research documents, whether they are published or not. The documents may come from teaching and research institutions in France or abroad, or from public or private research centers.
L'archive ouverte pluridisciplinaire HAL, est destinée au dépôt et à la diffusion de documents scientifiques de niveau recherche, publiés ou non, émanant des établissements d'enseignement et de recherche français ou étrangers, des laboratoires publics ou privés. 
Iron-fortified formula use in young children and association with socioeconomic factors in the French nationwide ELFE cohort

\section{Authors' full name and academic degrees:}

Anne--Sylvia Sacri, MD ${ }^{1,2,3,4^{*}}$; Blandine de Lauzon--Guillain, $\mathrm{PhD}^{3,5,6^{*}}$; Marie--Noëlle Dufourg, MD

${ }^{7}$; Corinne Bois, $\mathrm{MD}^{7,8}$; Marie Aline Charles, $\mathrm{PhD}^{3,5,7^{* *}}$; Martin Chalumeau, MD, $\mathrm{PhD}{ }^{1,2,3^{* *}}$

$*, * *$ : equal contribution

Authors' affiliations:

${ }^{1}$ Inserm, UMR1153, Centre de Recherche en Épidémiologie et Statistique Sorbonne Paris Cité (CRESS), équipe Épidémiologie Périnatale, Obstétricale et Pédiatrique (ÉPOPé), Labex GR--Ex, Paris, France

${ }^{2}$ Department of General Pediatrics and Pediatric Infectious Diseases, Necker--Enfants malades hospital, AP--HP, Paris, France

${ }^{3}$ Paris Descartes University, Sorbonne Paris Cité, France

${ }^{4}$ Paris Diderot University, Sorbonne Paris Cité, France

${ }^{5}$ Inserm, UMR 1153, CRESS, Early life research on later health Team (EAROH), Paris, France

${ }^{6}$ INRA, U 1125 Epidemiology and Biostatistics Sorbonne Paris Cité Center (CRESS), EAROH, Paris, F--75014 France

${ }^{7}$ Unité mixte Inserm--Ined--EFS ELFE, Ined, Paris, France

${ }^{8}$ Service départemental de PMI, Conseil départemental des Hauts--de--Seine, Nanterre, France

Short title: Iron--fortified formula use and socioeconomic factors

\section{Corresponding author:}

Blandine de Lauzon--Guillain. INSERM CRESS - Eq6 EAROH. Hôpital Paul Brousse, Batiment 15/16. 16 av. Paul Vaillant Couturier, 94807 Villejuif Cedex, France. Tel: +33145595019; Fax: +33147269454; E--mail: blandine.delauzon@inserm.fr 


\section{Abstract (197 words)}

Sacri A-S, de Lauzon-Guillain B, Dufourg M-D, Bois C, Charles M A, Chalumeau M. Ironfortified formula use in young children and association with socioeconomic factors in the French nationwide ELFE cohort.

Aim: To study the rate of iron--fortified infant formula (IFF) use in young children in France and its association with socioeconomic factors.

Methods: The ELFE national birth cohort included, in 2011, 18,329 living births in 349 hospitals randomly selected. The present analyses were restricted to children with follow--up at age 2 years. Milk consumption was evaluated by parental telephone interview, and its association with socioeconomic factors was studied.

Results: The 12,341 analyzed children had a mean age of 26 months; $50 \%$ were girls. Rate of IFF use before 2 years old and at 2 years old was $65 \%$ and $43 \%$, respectively. At age 2 years, use of IFF was lower with young age of the mother (adjusted OR [aOR]=0.4, 95\% CI: 0.3-0.5), low educational level $(\mathrm{aOR}=0.7,95 \%$ CI $0.6-0.9)$, high parity $(\mathrm{aOR}=0.3,95 \%$ CI $0.2-0.4)$, and mother smoking $(\mathrm{aOR}=0.8$, 95\% CI 0.7-0.9) as well as low household income (aOR=0.5, 95\% CI 0.4-0.7), and parents' unemployment $(\mathrm{aOR}=0.7,95 \%$ CI $0.5-0.9)$.

Conclusion: In this national population--based study, the rate of implementation of the ID prevention strategy was much lower at 2 years old than before 2 years old, and significantly lower in disadvantaged populations.

\section{Key notes}

- Iron deficiency in infants is a target of various preventive strategies worldwide and their implementation needs to be evaluated notably in high--risk populations

- Among the 12,341 children in the ELFE national population--based birth cohort, rate of iron-fortified formulas use was lower at 2 years old (43\%) than between 1 and 2 years old (65\%)

- Iron--fortified formula use was significantly lower in disadvantaged populations 
Keywords. Iron deficiency; primary prevention; infant formula; socioeconomic factors, populationbased cohort study 


\section{Introduction}

Iron deficiency (ID) is considered the most frequent micronutrient deficiency worldwide, including in industrialized countries, and is strongly suspected to be associated with adverse short- and long--term neurocognitive effects when it occurs in neonates and infants (1). In this context, ID is a target of various primary preventive strategies supported by medical societies and public health authorities, based on advices to parents for the consumption of naturally iron--rich foods during complementary feeding, and/or iron--fortification (e.g., formula or cereals) (2-4). In France, the preventive strategy involves both parental education during complementary feeding and consumption of iron--fortified milk at breastfeeding cessation (5). Iron--fortified formulas (IFFs) include "follow--on formula" with a mean iron content of $0.85 \mathrm{mg} / 100 \mathrm{ml}$ that has been recommended since the $1980 \mathrm{~s}$ for all non-breastfed infants from 6 to 12 months old and young child formula (called "growing--up formula") with a mean iron content of $1.13 \mathrm{mg} / 100 \mathrm{ml}$ that has been recommended since the 1990 s for all non-exclusively breastfed toddlers aged 10-12 to 36 months (5).

As for any universal health policy based on parental education, one of the main challenges for ID preventive strategies is to reach disadvantaged parents with low educational level or socioeconomic status, the main risk factors for ID in young children $(2,4,6,7)$. Thus, post--implementation surveys are crucial to evaluate the impact of preventive strategies, notably among these populations. The most recent evaluations of the implementation of the French fortification strategy consisted of national studies, in 2005 and 2013. The surveys showed that the mean iron intake among French young children was above the recommended $7 \mathrm{mg} /$ day until 24 months old but slightly lower (about 6.5 $\mathrm{mg} /$ day) after $(8,9)$. The rate of IFF use globally increased between 2005 and 2013 but gradually declined with age of children in both studies, from $80 \%$ and $89 \%$ at 6-7 months to $52 \%$ and $60 \%$ at 12-17 months, $27 \%$ and $57 \%$ at $18-23$ months, and $27 \%$ and $32 \%$ at $24-29$ months $(8,10)$. However, in these studies, recruitment was based on a quota method using few maternal socioeconomic variables with a likely selection bias. Furthermore, these studies were not able to evaluate associations between rate of IFF use and precise socioeconomic factors.

Our objective was to study the rate of IFF use in young children from 1 to 2 years old and its potential associations with socioeconomic factors by using data from the longitudinal French study 
since childhood (ELFE) cohort, the first national population--based longitudinal cohort in France, currently following children from birth to adulthood (11).

\section{Methods}

\section{General methodology}

The present study is based on data from the ELFE cohort whose purpose was to characterize the relation between the environment and the development, health and socialization of children. After receiving information from the investigator, written consent was obtained from the mothers of included children. Approvals for the survey were obtained from local ethics and administrative authorities (the Advisory Committee for the Treatment of Information on Health Research $\mathrm{n}^{\circ} 13.004$, the National Agency Regulating Data Protection $n^{\circ} 913071$, and the National Statistics Council $\left.\mathrm{n}^{\circ} 2013 \mathrm{X} 719 \mathrm{AU}\right)$. We used the Strengthening the Reporting of Observational Studies in Epidemiology (STROBE) guidelines to report this study (Table S1).

\section{Participant selection}

The ELFE cohort was launched in 2011 and enrolled 18,329 children for a projected 20--year follow-up. The protocol, design and recruitment procedures of the ELFE survey were previously described in detail (11). Briefly, participation in the survey was proposed to women giving birth in 349 maternity hospitals randomly selected (see below). Recruitment took place in 4 "waves" of surveys of 4 to 8 days totalizing 25 days covering the four seasons. Newborns and their mothers and fathers were eligible for data collection if they fulfilled the following criteria: infant born alive, term $\geq 33$ weeks' gestation, single or twin pregnancy, mothers aged 18 years and older, understanding the main implications of the study in one of four proposed languages (French, Arabic, English, Turkish), and living and planning to stay in France for at least 3 years.

The national recruitment was based on a two-stage (maternity hospitals then mothers) random stratified sampling design. The participation rate was $92 \%$ and $51 \%$ for contacted maternities and mothers, respectively (Figure 1). For the present study, young children whose parents withdrew 
consent within the first year or had missing data on the criteria of eligibility were excluded, and one twin in twin pregnancies was randomly selected to avoid family clusters. At the 2--year--old follow-up, children with no survey completed by a referent parent, with no data available on milk consumption or with maternal milk as their main source of milk, were excluded.

\section{Data collection and management}

The ELFE baseline assessment took place during the maternity hospital stay, with information collected by midwives during a face--to--face interview with the mother and from the mother's medical record. During the follow--up, telephone surveys took place at 2 months, 1 year and 2 years after delivery (11). In the present study, we used the following sociodemographic data: parents' age, country of birth, region of residence, educational level, professional status, smoking habits, mother living in a couple relationship, parity, family health coverage fully funded publicly as well as monthly household income. The following declarative dietary data were collected at the 2--year--old follow-up: any type of milk consumption from 1 to 2 years old, main type of milk consumption at 2 years old, and frequency of consumption of naturally iron--rich foods (meat, fish, and eggs) at 2 years old. The predefined categories of milk were IFF, cow's milk, or other types (soy, almond, rice or goat milk; other milk or vegetable beverage).

For statistical analyses, parental age was used as a fractional polynomial because there was a deviance to linearity and was presented in categories by convenience. Parents' country of birth was classified in two categories: France and other European countries versus countries with emerging and developing economies (CEE) according to the definition of the International monetary fund. Parents' educational level was classified in five categories according to the maximum level obtained. Parents' professional status was redefined in two categories, employed or not (including unemployed, housewife, retired, students, apprentices, and interns). Family health coverage fully funded publicly was also used because it is an indicator strongly linked to poverty in France. 
1

2

\section{Statistical analysis}

All descriptive data (rates) were weighted to take into account the inclusion procedure and biases related to non-consent in order to provide results representative of births in 2011 in France. Weighting also included calibration on margins from the state register's statistical data and the 2010 French National Perinatal study, which is an unbiased source of information about women delivering in France (12), on the following maternal variables: age, region, marital status, migration status, level of education and primiparity. This weighting was calculated for the sample follow--up at 2 months, as well as for the subsample that completed the questionnaire at 2 years.

We first described the children's milk consumption itinerary. Then, we described the rate of IFF use from 1 to 2 years old and studied uni- then multivariable associations with socioeconomic characteristics by using a logistic regression model including potential confounders selected according to a literature review and characteristics related to study design (maternal region of residence; size, level, and legal status of the maternity unit; and wave of recruitment). To avoid collinearity between maternal and paternal age and educational level, we used a summary variable to express the differences between maternal and paternal variables. The same approach was used to analyze the rate of IFF use at 2 years old.

Sensitivity analyses were performed, repeating descriptive analyses without the 2 year--old statistical weighting, and repeating all uni- and multivariable associations with the weighting. Missing data were not imputed. The analyses involved use of Stata/SE v13.1 (StataCorp, College Station, TX, USA).

\section{Results}

Participants

A total of 17,586 neonates were enrolled in the initial studied cohort (Figure 1). At the 2--year--old follow--up, 13,038 questionnaires (74\% of the studied cohort) were completed by the referent parent (99\% were mothers). For 554 (4\%) questionnaires, no information was available on milk consumption, and for $143(1 \%)$ young children, maternal milk was the main source of milk, which resulted in a population analyzed of 12,341 children ( $70 \%$ of the studied cohort). 
At the time of the interview, the mean age of children was 26 months (standard error of the mean [SEM]: 0.01), 50\% were girls, and $1 \%$ had cow's milk protein allergy according to parents. The mean age of mothers was 31 years (SEM: 0.07$), 15 \%$ were born in a CEE, $11 \%$ had a middle--school educational level, 31\% a high educational level, and 31\% were unemployed (Tables 1 and 2). The mean age of fathers was 34 years (SEM: 0.09), 15\% were born in a CEE, 12\% had a middle--school educational level, 27\% a high educational level, and 9\% were unemployed (Tables 1 and 2).

\section{IFF consumption itinerary and frequency of consumption of non--dairy naturally iron--rich foods}

From 1 to 2 years old, $65 \%$ of children received IFF, exclusively for $40 \%$ or with cow's milk for $24 \%$; 29\% received cow's milk only (Table 3). At 2 years old, 43\% received IFF as a main dairy source, and 50\% cow's milk. Among the children consuming IFF exclusively from 1 to 2 years old, 91\% continued to consume it at 2 years old, whereas 7\% consumed mainly cow's milk. Among the children consuming IFF with cow's milk from 1 to 2 years old, $24 \%$ consumed IFF mainly, whereas $74 \%$ continued to consume cow's milk mainly at 2 years old.

At 2 years old, $55 \%$ of children ate meat, fish,eggs once a day versus $2 \%$ less than several times a week (Table S2).

\section{Factors associated with IFF use}

On univariate analyses, the rate of regular use of IFF from 1 to 2 years old was significantly lower ( $p<0.05)$ with young maternal age $(54 \%<25$ years old versus $71 \% \geq 35$ years old), single motherhood ( $62 \%$ versus $66 \%$ with the mother living in a couple relationship), high parity ( $54 \%$ with $\geq 3$ children versus $71 \%$ primiparous), mother smoking (55\% versus $68 \%$ not smoking), low maternal educational level (58\% middle school versus $73 \%>2$ years of university), family health care coverage fully funded publicly (60\% versus $66 \%$ not), low monthly household income $(59 \%<1800$ euros versus $78 \% \geq$ 5000 euros), and parents' unemployment (58\% versus $68 \%$ both parents unemployed) (Table 1). This rate was significantly higher if the mother was born in a CEE $(73 \%$ versus $64 \%$ born in France/Europe). On multivariable logistic regression analysis, regular use of IFF from 1 to 2 years old 
was lower with low maternal age and educational level, high parity, mother smoking, and low monthly household income and higher with both parents born in a CEE (Table 1).

On univariate analyses, rate of IFF use as the main source of milk at 2 years old was significantly associated with similar socioeconomic factors as for IFF use from 1 to 2 years old, except mother's country of birth (Table 2). On multivariable logistic regression analysis, IFF use as the main source of milk at 2 years old was associated with parents' unemployment and similar factors as for IFF use from 1 to 2 years old but not country of birth (Table 2).

The sensitivity analyses showed similar results as the main results for descriptive data without 2 year--old statistical weighting and for uni- and multivariable associations with the weighting (Tables

\section{S3 and S4).}

\section{Discussion}

In industrialized countries, policies for ID prevention in young children are based on variable combinations of consumption of naturally iron--rich foods and/or fortification of specific food. Data to evaluate the implementation of these national strategies at a population level are limited, and those on the rate of IFF use after 1 year old are scarce. In this first French prospective nation--wide study, the rate of implementation of the ID prevention strategy by IFF use was much lower at 2 years old (43\%) than between 1 and 2 years old $(65 \%)$. These results are in line with those of a sample, with a likely selection bias, performed at the same time in 2013, more than 2 decades after this policy's launch (8). We confirm a global incre(2,3ase in the rate of IFF use in France, already noticed in previous non-random samples $(8,10)$. In the few other industrialized countries where the rate of IFF use was studied in the 2000s, the observed rates were below reported French ones: $30 \%$ to 53\% at 1 year old (13-17) to $3.5 \%$ to $35 \%$ at 2 years old $(13,15,18,19)$. In one small randomly selected sample in the Czech republic, the rate was close to those in the present study: $74 \%$ and $35 \%$ at 1 and 2 years old, respectively (18). The difference between France and other industrialized countries is probably related to the specificities of the French national recommendations that were periodically and strongly reaffirmed and that are shared both by the national health agency and the French society for pediatrics $(2,3,5)$. The main arguments supporting the French national strategy are that using IFF can replace 
the use of cow's milk, which is a known independent risk factor of ID, and that an IFF based strategy is theoretically easier to implement in day-to-day practice as compared with a balanced diet (20). The scientific arguments supporting the French specific position are the results of randomized controlled trials (21), and the findings from larger observational studies $(22,23)$. In five population-based or nearly population-based studies performed in United Kingdom, France and The Netherlands, the effectiveness of IFF consumption on iron status after 1 year old was shown, including after adjustment for non-diary iron intake, in four studies $(20,22-25)$. Therefore, IFF might be considered an effective means for ID prevention after 1 year when a balanced diet is difficult to achieve. However, these results will need confirmation because IFF provides non-heme iron, which is less absorbed than heme iron from meat and fish. In other industrialized countries, the American Academy of Pediatrics, the European Food Safety Authority (EFSA) and the European Society for Paediatric Gastroenterology Hepatology and Nutrition (ESPGHAN) do not recommend IFF as the main source of iron after 1 year old because they consider that iron intake from naturally iron-rich foods can achieve iron requirements at this age (2-4). Besides, the EFSA has indicated that "follow--on formulas" are adapted to iron requirements after 1 year old and that there is no need to recommend a specific composition for "growing--up formulas", a position endorsed recently by the $\operatorname{ESPGHAN}(26,27)$. The rate of use of other modes of ID prevention proposed in industrialized countries has rarely been studied. In the United States, the use of fortified cereals at 1 year old was estimated at only 46\% in 2005-2007 (16). Given the importance of preventing ID among young children, notably neurodevelopmental consequences, the current implementation level of the French national strategy should not be considered successful, and populations that are not reached by this preventive strategy should be identified. The ESPGHAN and EFSA have identified the ability of any ID prevention program to reach at--risk populations as crucial for its effectiveness $(3,4)$. In the present study, many factors associated with lack of implementation of the French strategy for ID prevention by IFF use, were linked to low economic level: low monthly household income, parents' unemployment, family health coverage fully funded publicly, or single motherhood. Low economic level is well known to be associated with ID $(2,4,7)$ and the lack of IFF use in some preliminary reports $(14,22)$. These results are also consistent with those showing that the early use of cow's milk is associated with low 
economic level in Europe and the United States (28). Thus, a direct financial barrier for IFF use seems possible given the higher mean prices as compared with cow's milk. Indeed, the additional cost for a daily intake of $500 \mathrm{ml}$ of IFF, as recommended in France, compared to an equivalent amount of cow's milk is about 10.9 to 28.3 euros per month (5). Such expenses represent between $0.6 \%$ and $1.6 \%$ of the poverty line for a French couple with a child less than 14 years old (i.e., monthly income $<1800$ euros), a situation observed in $9 \%$ of the families in our study . In France, the national recommendation of a daily intake of $500 \mathrm{ml}$ of IFF is not financially supported, in contrast to other universal programs aiming at preventing nutritional deficiencies such as vitamin D. Financial support may help to reach more disadvantaged families by removing financial barriers for the implementation of this national ID prevention strategy as proposed in programs involving food vouchers for lowincome populations in the United Kingdom or United States, although a variable effectiveness of these programs has been reported $(29,30)$.

The other factors we found associated with lack of implementation of the French strategy for ID prevention by IFF use were directly or indirectly related to non--financial barriers such as parental knowledge, practices, and experience related to recommended healthy behaviors: mother's young age, low educational level, mother smoking, and high parity. In other studies, adherence to nutritional guidelines in the first year of life has been found associated with high mother's educational level and age, independently of low economic level (15). In our study, most infants consumed non--dairy iron-rich foods at a frequency recommended by the national guidelines for complementary feeding. The observed strong independent association between lack of IFF use and high parity could have practical explanations: "same food for all children at home for convenience". Indeed, a higher number of children in the household is associated with the early introduction of meals similar to that for adults, before 2 years old (31). The association between high parity and low IFF use could also be related to increased parents' personal experience in nutrition and self--confidence regarding the absence of visible immediate consequences of ID, which is associated with only long--term neurodevelopmental impairment, barely detectable by parents on a routine basis (8). Thus, a better understanding of knowledge and attitudes related to non-financial barriers to IFF use will help develop adapted 
implementation strategies for ID prevention programs, as has been done in other fields of infant nutrition (32).

From 1 to 2 years old, the rate of IFF use was "paradoxically" associated with both parents born in a CEE, a result that could be attributed to an active recommendation of IFF to these families estimated at higher risk of ID from healthcare professionals or also to an active willingness to integrate from these families. Such paradoxical socio--behavioral profile was found for mothers' food consumption during pregnancy in the ELFE cohort (33).

\section{Limitations}

The main limitation of this study was related to selection bias. Indeed, despite efforts made to recruit and follow a representative national sample, agreement to participate in the study and adherence to the follow--up process was lower in the most disadvantaged families. This resulted in a sample more likely to have a high socioeconomic level than the French National Perinatal Survey (12). This attrition was in the range of existing birth cohorts in industrialized countries and the relation between high socioeconomic level and adherence to birth cohort follow--up is well described . This selection bias was taken into consideration in the analyses by using weighting at 2--year--old follow--up, and this correction did not significantly modify the uni- and multivariable analyses.

Other limitations are related to the design of the ELFE study and the lack of collection of blood samples in early infancy. Thus, we do not know if the IFF use in this population was associated with lower ID prevalence. We did not have precise data on iron intake, which prevented us from studying the role of IFF use compared to non--dairy iron--rich foods to reach iron requirements. An ongoing national study will contribute to addressing these questions [ClinicalTrials.gov Identifier: NCT02484274].

\section{Implications}

This nationwide study of a birth cohort compared to previous French data found an ascending rate of implementation of the recommendation of universal IFF use at exclusive breastfeeding cessation for ID prevention. This ascending rate was found in a population with a high socioeconomic level after 
1 statistical correction of the selection bias by weighting. The confirmation of a suboptimal

2 implementation among disadvantaged families reinforces the need to develop new strategies to reach

3 these families, who are at risk of ID, as shown in several studies including recent ones in France (2-4,

4 7, 22). Knowledge, attitudes, and practice surveys may be useful to better understand existing

5 implementation barriers and to prepare educational messages and tools for general and high-risk

6 populations.

7 


\section{Abbreviations}

2 CEE: country with Emerging economy

3 ID: iron deficiency

4 IFF: iron--fortified formula

5

6 Sources of funding:

7 Funding was received from Paris Diderot University - Sorbonne Paris Cité for a doctoral grant for Dr 8 Sacri.

9 Funding was received from institutions for another research project: Secteur Français des Aliments de 10 1'Enfance (Dr Sacri and Pr Chalumeau), French Ministry of Health "DGOS PHRC régional 2014 n 11 AOR14053” (Dr Sacri and Pr Chalumeau).

12

\section{Conflict of interest statement:}

14 The funders mentioned previously in "sources of funding" had no role in the study design, data

15 collection and analysis, the decision to publish, or the preparation of the manuscript. The authors have 16 no patents, products in development or marketed products to declare. 


\section{References}

1. Lozoff B, Jimenez E, Wolf AW. Long-term developmental outcome of infants with iron deficiency. $N$ Engl J Med 1991; 325 10:687-94.

2. Baker RD, Greer FR. Diagnosis and prevention of iron deficiency and iron-deficiency anemia in infants and young children (0-3 years of age). Pediatrics 2010; 126 5:1040-50.

3. EFSA. European Food Security Authority. Panel on Dietetic Products, Nutrition and Allergies (NDA). Scientific Opinion on nutrient requirements and dietary intakes of infants and young children in the European Union. European Food Security Authority (EFSA) Journal [serial online] 2013; 11 10:3408-511.

4. Domellof M, Braegger C, Campoy C, Colomb V, Decsi T, Fewtrell M, et al. Iron requirements of infants and toddlers. J Pediatr Gastroenterol Nutr 2014; 58 1:119-29.

5. Ghisolfi J, Vidailhet M, Fantino M, Bocquet A, Bresson JL, Briend A, et al. Lait de vache ou lait de croissance : quel lait recommander pour les enfants en bas age (1-3 ans) ? [French]. Arch Pediatr 2011; 18 4:355-8.

6. Attree P. A critical analysis of UK public health policies in relation to diet and nutrition in low-income households. Maternal \& child nutrition 2006; 2 2:67-78.

7. Sacri AS, Hercberg S, Gouya L, Levy C, Bocquet A, Blondel B, et al. Very low prevalence of iron deficiency among young French children: A national cross-sectional hospital-based survey. Maternal \& child nutrition 2018; 141.

8. Bocquet A, Vidailhet M. Nutri-Bebe 2013 Study Part 2. How do French mothers feed their young children? Arch Pediatr 2015; 2210 Suppl 1:10s7-s9.

9. Fantino M, Gourmet E. Apports nutritionnels en France en 2005 chez les enfants non allaités agés de moins de 36 mois [French]. Arch Pediatr 2008; 15 4:446-55.

10. Turberg-Romain C, Lelievre B, Le Heuzey MF. Conduite alimentaire des nourrissons et jeunes enfants ages de 1 à 36 mois en France : évolution des habitudes des mères [French]. Arch Pediatr 2007; 14 10:1250-8.

11. Vandentorren S, Bois C, Pirus C, Sarter H, Salines G, Leridon H, et al. Rationales, design and recruitment for the Elfe longitudinal study. BMC pediatrics 2009; 9:58.

12. Blondel B, Lelong N, Kermarrec M, Goffinet F. Trends in perinatal health in France from 1995 to 2010. Results from the French National Perinatal Surveys. Journal de gynecologie, obstetrique et biologie de la reproduction 2012; 41 4:e1-e15.

13. Grimes CA, Szymlek-Gay EA, Nicklas TA. Beverage Consumption among U.S. Children Aged 0-24 Months: National Health and Nutrition Examination Survey (NHANES). Nutrients 2017; 93.

14. Rossen LM, Simon AE, Herrick KA. Types of Infant Formulas Consumed in the United States. Clinical pediatrics 2016; 55 3:278-85.

15. Dubois L, Girard M. Social inequalities in infant feeding during the first year of life. The Longitudinal Study of Child Development in Quebec (LSCDQ 1998-2002). Public Health Nutr 2003; 6 8:773-83.

16. Grummer-Strawn LM, Scanlon KS, Fein SB. Infant feeding and feeding transitions during the first year of life. Pediatrics 2008; 122 Suppl 2:S36-42.

17. Thorisdottir AV, Thorsdottir I, Palsson GI. Nutrition and Iron Status of 1-Year Olds following a Revision in Infant Dietary Recommendations. Anemia 2011; 2011:986303.

18. Kudlova E, Rames J. Food consumption and feeding patterns of Czech infants and toddlers living in Prague. Eur J Clin Nutr 2007; 61 2:239-47.

19. Emmett PM, Jones LR. Diet and growth in infancy: relationship to socioeconomic background and to health and development in the Avon Longitudinal Study of Parents and Children. Nutr Rev 2014; 72 8:483-506.

20. Sidnell A, Pigat S, Gibson S, O'Connor R, Connolly A, Sterecka S, et al. Nutrient intakes and iron and vitamin D status differ depending on main milk consumed by UK children aged 1218 months - secondary analysis from the Diet and Nutrition Survey of Infants and Young Children. J Nutr Sci 2016; 5:e32.

21. Akkermans MD, Eussen SR, van der Horst-Graat JM, van Elburg RM, van Goudoever JB, Brus F. A micronutrient-fortified young-child formula improves the iron and vitamin D status 
of healthy young European children: a randomized, double-blind controlled trial. Am J Clin Nutr 2017; 105 2:391-9.

22. Vincelet C, Foucault C. [Measuring iron levels relative to the type of milk consumed within a population of 16 to 18 month old French infants]. Sante Publique 2005; 17 3:339-46.

23. Sacri AS, Bocquet A, de Montalembert M, Hercberg S, Gouya L, Blondel B, et al. "Growingup" milk and socio-economic risk factors of iron deficiency at 24 months old in the general population in France [oral communication], 7th European Academy of Paediatric Societies (EAPS) congress, 2018.

24. Hopkins D, Emmett P, Steer C, Rogers I, Noble S, Emond A. Infant feeding in the second 6 months of life related to iron status: an observational study. Arch Dis Child 2007; 92 10:8504.

25. Uijterschout L, Vloemans J, Vos R, Teunisse PP, Hudig C, Bubbers S, et al. Prevalence and risk factors of iron deficiency in healthy young children in the southwestern Netherlands. $J$ Pediatr Gastroenterol Nutr 2014; 58 2:193-8.

26. 3696EFSA. 'Growing-up' formula: No additional value to a balanced diet, says EFSA.

27. Hojsak I, Bronsky J, Campoy C, Domellof M, Embleton N, Fidler Mis N, et al. Young Child Formula: A Position Paper by the ESPGHAN Committee on Nutrition. J Pediatr Gastroenterol Nutr 2018; 66 1:177-85.

28. Wijndaele K, Lakshman R, Landsbaugh JR, Ong KK, Ogilvie D. Determinants of early weaning and use of unmodified cow's milk in infants: a systematic review. Journal of the American Dietetic Association 2009; 109 12:2017-28.

29. Ng SW, Hollingsworth BA, Busey EA, Wandell JL, Miles DR, Poti JM. Federal Nutrition Program Revisions Impact Low-income Households' Food Purchases. Am J Prev Med 2018; 54 3:403-12.

30. McFadden A, Green JM, Williams V, McLeish J, McCormick F, Fox-Rushby J, et al. Can food vouchers improve nutrition and reduce health inequalities in low-income mothers and young children: a multi-method evaluation of the experiences of beneficiaries and practitioners of the Healthy Start programme in England. BMC public health 2014; 14:148.

31. Saldiva SR, Escuder MM, Mondini L, Levy RB, Venancio SI. Feeding habits of children aged 6 to 12 months and associated maternal factors. Jornal de pediatria 2007; 83 1:53-8.

32. 3698United States Department of Agriculture. Women, Infants and Children (WIC) Final Rule: Revisions in the WIC Food Packages.

33. Kadawathagedara M, Kersuzan C, Wagner S, Tichit C, Gojard S, Charles MA, et al. Adéquation des consommations alimentaires des femmes enceintes de l'étude ELFE aux recommandations du Programme national nutrition santé [French]. Cahiers de Nutrition et de Diététique 2017; 52 2:78-88. 
1 Table 1. Socioeconomic characteristics of participants and association with use of iron--fortified

2 formula (IFF) from 1 to 2 year--old

\begin{tabular}{|c|c|c|c|c|c|}
\hline \multirow[t]{3}{*}{ Characteristics } & \multirow{3}{*}{$\begin{array}{l}\text { Proportion, } \\
\% \\
\mathrm{n}=12341\end{array}$} & \multicolumn{4}{|c|}{ Use of iron--fortified formula (IFF) ${ }^{1}$} \\
\hline & & IFF,$+ \%$ & IFF -, \% & $\begin{array}{l}\text { Crude OR } \\
(95 \% \text { CI })\end{array}$ & $\begin{array}{l}\text { Adjusted OR } \\
(95 \% \mathrm{CI})\end{array}$ \\
\hline & & $65 \%$ & $35 \%$ & & \\
\hline \multicolumn{6}{|l|}{ Mother's age (years) } \\
\hline$\geq 35$ & 23 & 71 & 29 & - & - \\
\hline $30-34$ & 34 & 66 & 34 & $0.87(0.79-0.96)$ & $0.75(0.66-0.85)$ \\
\hline $25-29$ & 31 & 65 & 35 & $0.75(0.67-0.83)$ & $0.57(0.49-0.66)$ \\
\hline$<25$ & 12 & 54 & 46 & $0.44(0.38-0.52)$ & $0.36(0.29-0.45)$ \\
\hline \multicolumn{6}{|c|}{ Age difference between parents } \\
\hline Same age & 53 & 67 & 33 & - & - \\
\hline Father younger & 8 & 67 & 33 & $1.01(0.84-1.23)$ & $0.97(0.82-0.14)$ \\
\hline Mother younger & 39 & 63 & 37 & $0.86(0.77-0.95)$ & $1.10(0.99-1.22)$ \\
\hline \multicolumn{6}{|l|}{ Sex } \\
\hline Male & 50 & 65 & 35 & - & - \\
\hline Female & 50 & 66 & 34 & $1.03(0.96-1.11)$ & $1.06(0.98-1.16)$ \\
\hline \multicolumn{6}{|l|}{ Single motherhood } \\
\hline No & 93 & 66 & 34 & - & - \\
\hline Yes & 7 & 62 & 38 & $0.79(0.64-0.96)$ & $0.95(0.59-1.54)$ \\
\hline \multicolumn{6}{|l|}{ Parity } \\
\hline 1 & 44 & 71 & 29 & - & - \\
\hline 2 & 35 & 63 & 37 & $0.68(0.62-0.74)$ & $0.54(0.48-0.59)$ \\
\hline 3 & 14 & 59 & 41 & $0.54(0.48-0.61)$ & $0.39(0.34-0.45)$ \\
\hline$\geq 4$ & 7 & 54 & 46 & $0.41(0.35-0.49)$ & $0.29(0.23-0.36)$ \\
\hline \multicolumn{6}{|l|}{ Mother's country of birth } \\
\hline France/ Europe & 85 & 64 & 36 & - & - \\
\hline $\mathrm{CEE}^{3}$ & 15 & 73 & 27 & $1.54(1.28-1.85)$ & - \\
\hline \multicolumn{6}{|l|}{ Father's country of birth } \\
\hline France/ Europe & 85 & 65 & 35 & - & - \\
\hline $\mathrm{CEE}$ & 15 & 69 & 31 & $1.06(0.93-1.22)$ & - \\
\hline \multicolumn{6}{|l|}{ Parents' country of birth } \\
\hline Both from France/ Europe & 79 & 64 & 36 & - & - \\
\hline One from CEE & 12 & 68 & 32 & $1.13(0.98-1.30)$ & $1.13(0.96-1.34)$ \\
\hline Both from CEE & 9 & 72 & 28 & $1.30(1.06-1.59)$ & $1.55(1.17-2.06)$ \\
\hline \multicolumn{6}{|l|}{ Mother smoking } \\
\hline No & 78 & 68 & 32 & - & - \\
\hline Yes & 22 & 55 & 45 & $0.61(0.55-0.67)$ & $0.77(0.69-0.86)$ \\
\hline \multicolumn{6}{|l|}{ Mother's education level } \\
\hline$>2$ years of university & 31 & 73 & 27 & - & - \\
\hline 2 years of university & 20 & 69 & 31 & $0.79(0.71-0.88)$ & $0.94(0.83-1.06)$ \\
\hline $\begin{array}{l}\text { General high school } \\
\text { diploma }\end{array}$ & 19 & 62 & 38 & $0.57(0.51-0.64)$ & $0.84(0.73-0.96)$ \\
\hline $\begin{array}{l}\text { Professional high school } \\
\text { diploma }\end{array}$ & 19 & 56 & 44 & $0.44(0.39-0.49)$ & $0.76(0.64-0.90)$ \\
\hline Middle school & 11 & 58 & 42 & $0.48(0.41-0.57)$ & $0.84(0.66-1.09)$ \\
\hline \multicolumn{6}{|c|}{$\begin{array}{l}\text { Education level difference between } \\
\text { parents }\end{array}$} \\
\hline Same level & 39 & 67 & 33 & - & - \\
\hline Father with lower level & 38 & 66 & 34 & $0.85(0.78-0.93)$ & $0.94(0.85-1.04)$ \\
\hline Mother with lower level & 23 & 62 & 38 & $0.75(0.68-0.83)$ & $1.01(0.89-1.15)$ \\
\hline \multicolumn{6}{|c|}{ Health coverage fully funded publicly ${ }^{4}$} \\
\hline No & 88 & 66 & 34 & - & - \\
\hline Yes & 12 & 60 & 40 & $0.69(0.59-0.81)$ & - \\
\hline
\end{tabular}




\begin{tabular}{|c|c|c|c|c|c|}
\hline \multirow[t]{3}{*}{ Characteristics } & \multirow{3}{*}{$\begin{array}{l}\text { Proportion, } \\
\% \\
\mathrm{n}=12341\end{array}$} & \multicolumn{4}{|c|}{ Use of iron--fortified formula (IFF) $^{1}$} \\
\hline & & IFF,$+ \%$ & IFF -, \% & $\begin{array}{l}\text { Crude OR } \\
(95 \% \text { CI })\end{array}$ & $\begin{array}{l}\text { Adjusted OR } \\
(95 \% \text { CI })\end{array}$ \\
\hline & & $65 \%$ & $35 \%$ & & \\
\hline \multicolumn{6}{|c|}{ Monthly household income (euros) } \\
\hline$\geq 5000$ & 10 & 78 & 22 & - & - \\
\hline $4000-4999$ & 11 & 73 & 27 & $0.76(0.65-0.90)$ & $0.83(0.70-0.98)$ \\
\hline $3100-3999$ & 19 & 68 & 32 & $0.63(0.55-0.73)$ & $0.78(0.66-0.91)$ \\
\hline $2500-3099$ & 26 & 63 & 37 & $0.50(0.43-0.57)$ & $0.68(0.57-0.80)$ \\
\hline $1800-2499$ & 18 & 57 & 43 & $0.39(0.34-0.46)$ & $0.58(0.48-0.71)$ \\
\hline$<1800$ & 16 & 59 & 41 & $0.38(0.32-0.45)$ & $0.62(0.49-0.79)$ \\
\hline \multicolumn{6}{|c|}{ Mother's employment } \\
\hline Employed & 69 & 68 & 32 & - & - \\
\hline Unemployed & 31 & 58 & 42 & $0.63(0.57-0.69)$ & \\
\hline \multicolumn{6}{|l|}{ Father's employment } \\
\hline Employed & 91 & 66 & 34 & - & - \\
\hline Unemployed & 9 & 62 & 38 & $0.78(0.68-0.91)$ & \\
\hline \multicolumn{6}{|l|}{ Parents' employment } \\
\hline Both employed & 67 & 68 & 32 & - & $0.87(0.78-0.97)$ \\
\hline One unemployed & 29 & 59 & 41 & $0.67(0.61-0.74)$ & $0.83(0.63-1.11)$ \\
\hline Both unemployed & 4 & 58 & 42 & $0.58(0.46-0.74)$ & $0.93(0.64-1.33)$ \\
\hline
\end{tabular}

$1{ }^{1}$ percentages of IFF use are weighted and the measures of associations (odds--ratios) are non--weighted

$2{ }^{2}$ adjusted odds--ratios for the following variables: mother's age, age difference between parents, child's sex, single

3 motherhood, parents' country of birth, mother's smoking, mother's education level, education level difference between

4 parents, monthly household income, and parents' employment

$5 \quad{ }^{3}$ CEE: countries with emerging and developing economies

$6{ }^{4}$ health coverage fully funded publicly, an indicator strongly linked to poverty in France

7

8 Abbreviations: $\mathrm{CI}=$ confidence interval, $\mathrm{n}=$ number of participants, $\mathrm{OR}=$ odds ratio

9 
Table 2. Socioeconomic characteristics of participants and association with use of iron--fortified formula XIFF) at 2 year--old

\begin{tabular}{|c|c|c|c|c|c|}
\hline \multirow[t]{3}{*}{ Characteristics } & \multirow{3}{*}{$\begin{array}{l}\text { Proportion, } \\
\% \\
\mathrm{n}=12341\end{array}$} & \multicolumn{4}{|c|}{ Use of iron--fortified formula (IFF) $^{1}$} \\
\hline & & & IFF -, \% & $\begin{array}{l}\text { Crude OR } \\
\text { (95\% CI) }\end{array}$ & $\begin{array}{l}\text { Adjusted OR }{ }^{2} \\
(95 \% \mathrm{CI})\end{array}$ \\
\hline & & $43 \%$ & $57 \%$ & & \\
\hline \multicolumn{6}{|l|}{ Mother's age (years) } \\
\hline$\geq 35$ & 23 & 50 & 50 & - & - \\
\hline $30-34$ & 34 & 46 & 54 & $0.90(0.82-0.99)$ & $0.75(0.67-0.85)$ \\
\hline $25-29$ & 31 & 40 & 60 & $0.68(0.61-0.74)$ & $0.54(0.47-0.61)$ \\
\hline$<25$ & 12 & 27 & 73 & $0.36(0.30-0.42)$ & $0.37(0.29-0.46)$ \\
\hline \multicolumn{6}{|c|}{ Age difference between parents } \\
\hline Same age & 53 & 46 & 54 & - & - \\
\hline Father younger & 8 & 40 & 60 & $0.90(0.79-1.03)$ & $0.90(0.77-1.04)$ \\
\hline Mother younger & 39 & 39 & 61 & $0.79(0.73-0.85)$ & $1.04(0.94-1.14)$ \\
\hline \multicolumn{6}{|l|}{ Sex } \\
\hline Male & 50 & 42 & 58 & - & - \\
\hline Female & 50 & 43 & 57 & $1.04(0.97-1.12)$ & $1.07(0.99-1.16)$ \\
\hline \multicolumn{6}{|l|}{ Single motherhood } \\
\hline No & 93 & 43 & 57 & - & - \\
\hline Yes & 7 & 35 & 65 & $0.68(0.56-0.83)$ & $1.23(0.77-1.97)$ \\
\hline \multicolumn{6}{|l|}{ Parity } \\
\hline 1 & 44 & 49 & 51 & - & - \\
\hline 2 & 35 & 40 & 60 & $0.66(0.61-0.72)$ & $0.51(0.47-0.56)$ \\
\hline 3 & 14 & 37 & 63 & $0.57(0.51-0.64)$ & $0.40(0.35-0.46)$ \\
\hline$\geq 4$ & 7 & 34 & 66 & $0.40(0.33-0.47)$ & $0.29(0.23-0.36)$ \\
\hline \multicolumn{6}{|l|}{ Mother's country of birth } \\
\hline France/ Europe & 85 & 42 & 58 & - & - \\
\hline $\mathrm{CEE}^{3}$ & 15 & 47 & 53 & $1.10(0.97-1.26)$ & - \\
\hline \multicolumn{6}{|l|}{ Father's country of birth } \\
\hline France/ Europe & 85 & 43 & 57 & - & - \\
\hline CEE & 15 & 41 & 59 & $0.83(0.73-0.94)$ & - \\
\hline \multicolumn{6}{|l|}{ Parents' country of birth } \\
\hline Both from France/ Europe & 79 & 43 & 57 & - & - \\
\hline One from CEE & 12 & 43 & 57 & $0.99(0.87-1.12)$ & $1.04(0.89-1.21)$ \\
\hline Both from CEE & 9 & 44 & 56 & $0.89(0.74-1.07)$ & $1.24(0.95-1.61)$ \\
\hline \multicolumn{6}{|l|}{ Mother smoking } \\
\hline No & 78 & 46 & 54 & - & - \\
\hline Yes & 22 & 31 & 69 & $0.58(0.53-0.64)$ & $0.77(0.69-0.86)$ \\
\hline \multicolumn{6}{|l|}{ Mother's education level } \\
\hline$>2$ years of university & 31 & 53 & 47 & - & - \\
\hline 2 years of university & 20 & 48 & 52 & $0.79(0.72-0.87)$ & $0.96(0.86-1.07)$ \\
\hline $\begin{array}{l}\text { General high school } \\
\text { diploma }\end{array}$ & 19 & 38 & 62 & $0.51(0.46-0.57)$ & $0.77(0.67-0.88)$ \\
\hline $\begin{array}{l}\text { Professional high school } \\
\quad \text { diploma }\end{array}$ & 19 & 31 & 69 & $0.36(0.32-0.40)$ & $0.67(0.57-0.80)$ \\
\hline Middle school & 11 & 32 & 68 & $0.37(0.31-0.44)$ & $0.73(0.57-0.95)$ \\
\hline \multicolumn{6}{|c|}{$\begin{array}{l}\text { Education level difference between } \\
\text { parents }\end{array}$} \\
\hline Same level & 39 & 45 & 55 & - & - \\
\hline Father with lower level & 38 & 43 & 57 & $0.84(0.78-0.91)$ & $0.95(0.86-1.04)$ \\
\hline Mother with lower level & 23 & 40 & 60 & $0.70(0.64-0.78)$ & $1.02(0.90-1.15)$ \\
\hline \multicolumn{6}{|c|}{ Health coverage fully funded publicly ${ }^{4}$} \\
\hline No & 88 & 44 & 56 & - & - \\
\hline Yes & 12 & 33 & 67 & $0.55(0.47-0.64)$ & - \\
\hline
\end{tabular}




\begin{tabular}{|c|c|c|c|c|c|}
\hline \multirow[t]{3}{*}{ Characteristics } & \multirow{3}{*}{$\begin{array}{l}\text { Proportion, } \\
\% \\
\mathrm{n}=12341\end{array}$} & \multicolumn{4}{|c|}{ Use of iron--fortified formula (IFF) $^{1}$} \\
\hline & & IFF,$+ \%$ & IFF -, \% & $\begin{array}{l}\text { Crude OR } \\
(95 \% \text { CI })\end{array}$ & $\begin{array}{l}\text { Adjusted OR } \\
(95 \% \text { CI })\end{array}$ \\
\hline & & $43 \%$ & $57 \%$ & & \\
\hline \multicolumn{6}{|c|}{ Monthly household income (euros) } \\
\hline$\geq 5000$ & 10 & 61 & 39 & - & - \\
\hline $4000-4999$ & 11 & 54 & 46 & $0.78(0.68-0.90)$ & $0.85(0.74-0.99)$ \\
\hline $3100-3999$ & 19 & 48 & 52 & $0.64(0.57-0.73)$ & $0.78(0.68-0.90)$ \\
\hline $2500-3099$ & 26 & 40 & 60 & $0.46(0.41-0.52)$ & $0.65(0.56-0.75)$ \\
\hline $1800-2499$ & 18 & 34 & 66 & $0.35(0.31-0.41)$ & $0.54(0.45-0.65)$ \\
\hline$<1800$ & 16 & 32 & 68 & $0.30(0.25-0.35)$ & $0.52(0.41-0.65)$ \\
\hline \multicolumn{6}{|c|}{ Mother's employment } \\
\hline Employed & 69 & 47 & 53 & - & - \\
\hline Unemployed & 31 & 35 & 65 & $0.58(0.53-0.63)$ & - \\
\hline \multicolumn{6}{|l|}{ Father's employment } \\
\hline Employed & 91 & 45 & 55 & - & - \\
\hline Unemployed & 9 & 32 & 68 & $0.64(0.56-0.74)$ & - \\
\hline \multicolumn{6}{|l|}{ Parents' employment } \\
\hline Both employed & 67 & 48 & 52 & - & - \\
\hline One unemployed & 29 & 36 & 64 & $0.61(0.56-0.67)$ & $0.82(0.73-0.91)$ \\
\hline Both unemployed & 4 & 30 & 70 & $0.45(0.35-0.58)$ & $0.73(0.54-0.98)$ \\
\hline
\end{tabular}

$1{ }^{1}$ percentages of IFF use are weighted and the measures of associations (odds--ratios) are non--weighted

$22^{2}$ adjusted odds--ratios for the following variables: mother's age, age difference between parents, child's sex, single

3 motherhood, parents' country of birth, mother's smoking, mother's education level, education level difference between

4 parents, monthly household income, and parents' employment

$5 \quad{ }^{3}$ CEE: countries with emerging and developing economies

$6{ }^{4}$ health coverage fully funded publicly, an indicator strongly linked to poverty in France

7

8 Abbreviations: $\mathrm{CI}=$ confidence interval, $\mathrm{n}=$ number of participants, $\mathrm{OR}=$ odds ratio

9 
1 Table 3. Milk consumption from 1 to 2 year--old and at 2 years old

\begin{tabular}{|c|c|c|c|c|c|}
\hline \multirow[t]{2}{*}{ Milk consumption } & \multicolumn{4}{|l|}{ At 2 year--old } & \multirow{3}{*}{$\begin{array}{l}\text { Proportion } \\
\text { Total }\end{array}$} \\
\hline & $\begin{array}{l}\text { Iron--fortified } \\
\text { formula }\end{array}$ & Cow's milk & $\begin{array}{l}\text { Other type of } \\
\text { milk }^{1}\end{array}$ & No milk & \\
\hline \multicolumn{5}{|l|}{ From 1 to 2 year--old } & \\
\hline $\begin{array}{l}\text { Iron--fortified formula } \\
\text { only }\end{array}$ & $91 \%^{2}$ & $7 \%$ & $\sim 0 \%$ & $2 \%$ & $40 \%$ \\
\hline $\begin{array}{l}\text { Iron--fortified formula } \\
\text { and cow's milk }\end{array}$ & $24 \%$ & $74 \%$ & $1 \%$ & $1 \%$ & $24 \%$ \\
\hline $\begin{array}{l}\text { Iron--fortified formula } \\
\text { and another type of milk }{ }^{1}\end{array}$ & $60 \%$ & $11 \%$ & $26 \%$ & $3 \%$ & $1 \%$ \\
\hline Cow's milk only & $\sim 0 \%$ & $98 \%$ & $\sim 0 \%$ & $2 \%$ & $29 \%$ \\
\hline $\begin{array}{l}\text { Cow's milk and another } \\
\text { type of milk }\end{array}$ & 0 & $79 \%$ & $19 \%$ & $2 \%$ & $1 \%$ \\
\hline Another type of milk only & $3 \%$ & $5 \%$ & $85 \%$ & $7 \%$ & $2 \%$ \\
\hline No milk & $7 \%$ & $25 \%$ & $3 \%$ & $65 \%$ & $3 \%$ \\
\hline Proportion total & $43 \%$ & $50 \%$ & $3 \%$ & $4 \%$ & $100 \%$ \\
\hline
\end{tabular}

2 soy milk, almond milk, rice milk, goat's milk, other vegetable beverage, other animal

3 beverage

$4{ }^{2}$ row percentage

5 


\section{$1 \quad$ Figure legend}

2 *WG: weeks' gestation

\begin{tabular}{l}
$\begin{array}{l}\text { Eligible participants ELFE } \\
\text { in } 2011 \\
\mathrm{n}=36099\end{array}$ \\
$\begin{array}{l}\text { Initial ELFE cohort in } 2011 \\
\mathrm{n}=18329\end{array}$ \\
\hline
\end{tabular}

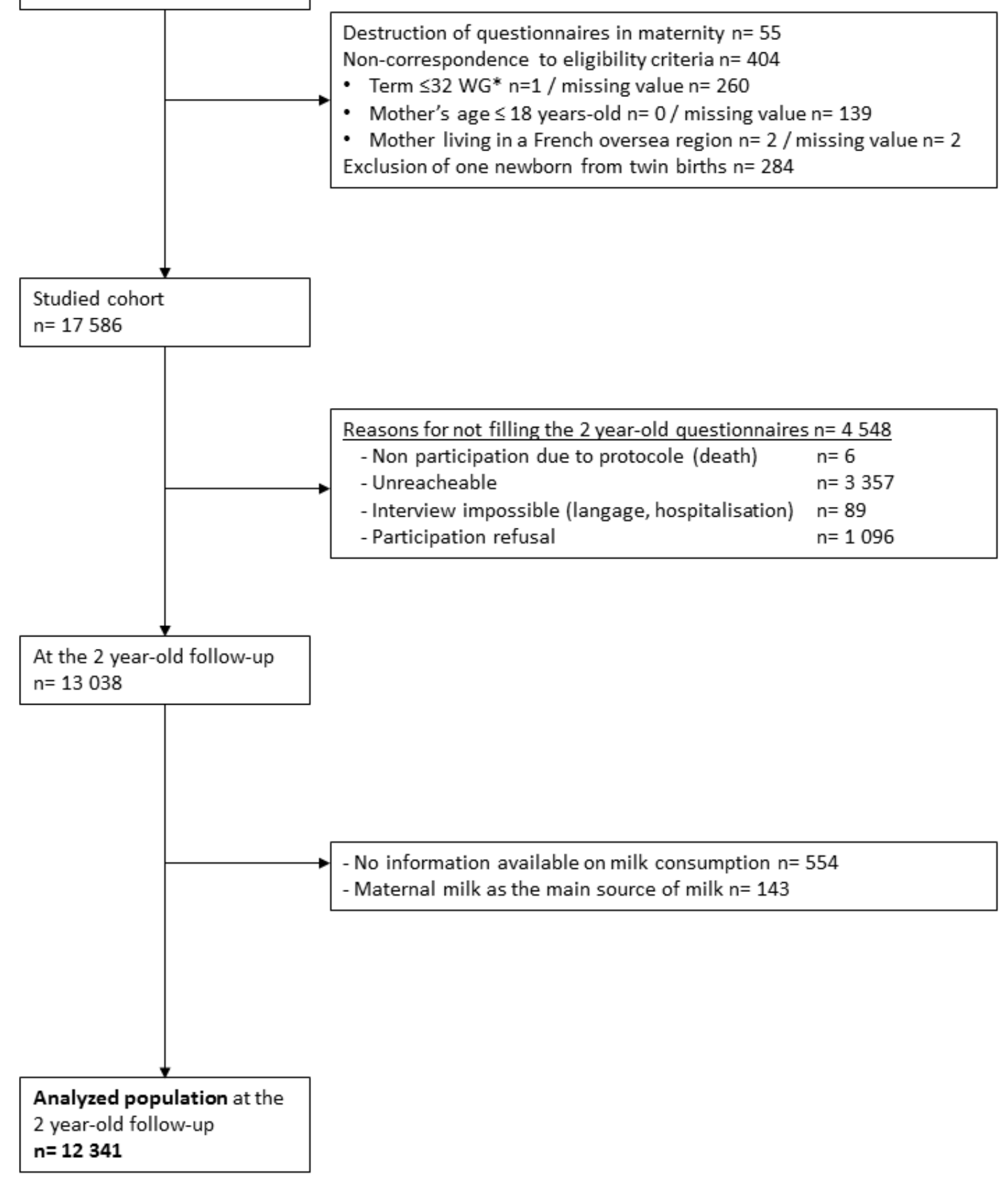


1 Figure 1. Flow chart of the participants in the study 